DOI: 10.17805/trudy.2017.6.2.

\title{
НАУЧНО-МЕТОДИЧЕСКИЕ ПОДХОДЫ К ФОРМИРОВАНИЮ СИСТЕМНО-ИНТУИТИВНОГО МЫШЛЕНИЯ СТУДЕНТОВ-ЮРИСТОВ КОЛЛЕДЖА НА ЗАНЯТИЯХ ИНОСТРАННОГО ЯЗЫКА
}

\author{
Э. А. Картакаева
}

Московский гуманитарный университет

\begin{abstract}
Аннотация: В статье рассмотрены вопросы формирования личности, обладающей системно-интуитивным мышлением, на занятиях иностранного языка студентов среднего профессионального образования юридическо20 направления. Сделаны выводы о методах, способствующих положительной динамике развития системно-интуитивного мышления студентов.
\end{abstract}

Ключевые слова: образовательная политика; системно-интуитивное мышление; иностранный язык; деловая игра

\section{METHODOLOGICAL APPROACHES TO THE FORMATION OF SYSTEMATIC INTUITIVE THINKING OF COLLEGE LAW STUDENTS DURING FOREIGN LANGUAGE CLASSES}

\author{
E. A. Kartakayeva \\ Moscow University for the Humanities
}

Abstract: The article considers issues connected with the formation of a personality having systematic intuitive thinking during foreign language classes of secondary vocational education law students. The author draws conclusions on the methods promoting positive dynamics of the development of students' systematic intuitive thinking.

Keywords: educational policy; systematic intuitive thinking; foreign language; business game

В настоящее время человечество оказалось лицом к лицу перед решением большого количества глобальных проблем. К ним, в частности, можно отнести: осознание исчерпаемости мировых природных ресурсов; экологические проблемы; проблемы обеспечения человечества необходимыми ресурсами (продовольствием, промышленным сырьем, энергией и т. д.); проблемы здоровья человека; существование большого количества людей, живущих за чертой бедности; регулирование стреми- 
тельного роста населения в развивающихся странах и мн. др. Образование XXI века является ключом к решению этих глобальных проблем современного мира (Ильинский, 2012).

Образовательная политика России, выражая общенациональные интересы в сфере образования, учитывает и общие тенденции мирового развития, обусловливающие необходимость существенных изменений в системе образования. Разумеется, возникновение и рост глобальных проблем, которые могут быть решены лишь в результате сотрудничества в рамках международного сообщества, требуют формирования современного мышления у молодого поколения.

Анализ возникших глобальных проблем современности показывает, что многие из этих проблем не носили бы столь серьезный характер, если в ходе прогрессивного развития человечества, внедрения достижений науки и техники использовался системный подход, опирающийся на всесторонний, всеобъемлющий анализ и прогноз возможных последствий от внедрения тех или иных достижений науки и техники. Сегодня настоятельно требуются исследования психолого-педагогических проблем развивающего обучения, одним из важнейших элементов которого является развитие системного мышления обучающихся.

В этой связи, актуальной задачей является создание такой системы обучения, которая позволит обеспечить формирование личности, обладающей системным мышлением, направленным на выявление всей конкретной сложности сочетания тесно взаимосвязанных факторов, личности, способной эффективно решать проблемы в различных областях человеческой деятельности.

Успешное развитие системного мышления возможно только в том случае, если педагогическая наука будет этим заниматься не фрагментарно, а охватывать этим процессом все дисциплины, изучаемые в среднем профессиональном и высшем образовании. Только в этом случае мышление будет по-настоящему системным.

Особенностью нынешнего периода развития современного российского общества является то, что роль юридического образования, юридической науки значительно возросли. Это связано со следующими причинами: нет четко выраженной идеологии в обществе, отсутствуют ориентиры в идеалах общества, изменения в социально-экономической области определяют необходимость совершенствования правотворческой, правоприменительной, правоохранительной, научно-исследовательской, педагогической деятельности.

Следует отметить, что, наряду с развитым системным мышлением, специалист, работающий в юридической сфере, должен также обладать и хорошим интуитивным мышлением. Это связано с тем, что юристу часто приходится сталкиваться с ситуацией, когда существует неопреде- 
ленность в ее характеристике, в частности, расследование обстоятельств дела, работа с людьми. Развитие системно-интуитивного мышления играет большую роль не только для обеспечения успешной профессиональной деятельности юриста, но и успешной деятельности в иных областях, включая и личную жизнь.

Сейчас в мире активно осуществляются интеграционные процессы и расширяется международное сотрудничество, возрастает необходимость хорошего знания иностранных языков у обучающихся в системе средней профессиональной и высшей школы. Юрист, владеющий иностранным языком, имеет больше возможностей для своего профессионального роста. Перед ним открываются большие возможности в плане международного сотрудничества. Он может быть незаменимым сотрудником в любой компании, занимающейся международной экономической деятельностью. У юриста, отлично владеющего иностранным языком, занимающегося научной работой, будет доступ к большому количеству источников информации на иностранном языке, он сможет писать статьи на иностранном языке и публиковаться в иностранных журналах.

Иностранный язык является междисциплинарным учебным предметом, так как на занятиях по иностранному языку речь может идти о различных предметных областях. Можно констатировать, что иностранный язык способствует значительному расширению кругозора студентов средней профессиональной и высшей школы. Поэтому одним из основных компонентов системы среднего профессионального и высшего образования является обучение иностранному языку. Анализ практики обучения студентов иностранному языку показывает, что существует противоречие между возрастающими требованиями к уровню профессиональных компетенций выпускников образовательных организаций и, как следствие этого, возрастанием требований к уровню их системно-интуитивного мышления и недостаточным количеством учебно-методических материалов, используемых в образовательном процессе и позволяющих осуществлять развитие системно-интуитивного мышления.

Все вышеизложенные аспекты развития современного образования, а также указанное противоречие и определяют актуальность работы, связанной с вопросами формирования системно-интуитивного мышления на занятиях иностранного языка у студентов колледжа Московского гуманитарного университета, обучающихся специальности 40.02.01 - Право и организация социального обеспечения.

Методологической основой рассматриваемого вопроса являются:

- принципы организации и проведения научно-педагогического исследования (Ю. К. Бабанский, В. И. Загвязинский, И. А. Зимняя, А. М. Новиков, М. Н. Скаткин и др.), 
- теория развивающего обучения Л. С. Выготского и его последователей (А. Н. Леонтьева, П. Я. Гальперина, Б. Г. Ананьева и др.), а также В. И. Андреева, Д. В. Вилькеева, И. Я. Лернера, А. М. Матюшкина, М. И. Махмутова, М. Н. Скаткина, А. В. Хуторского,

- теория учебной деятельности студентов, способствующая применению форм и методов развития умений системного мышления (Н. М. Таланчук, 3. А. Решетова, В. Н. Корчагин и др.),

- особенности приемов и способов организации учебной деятельности для развития продуктивного мышления обучающихся (В. И. Андреев, Л. И. Анцыферова, Ю. К. Бабанский, Б. А. Глинский, В. И. Горовая, Л. Д. Деулина, А. А. Зиновьев, М. С. Каган, Н. В. Кузьмина, А. М. Матюшкин, Н. Н. Нечаев, М. М. Левина и др.),

- теория системного мышления (Н. Т. Абрамова, Э. Г. Афанасьев, И. В. Блауберг, В. Т. Мещеряков, Н. Ф. Овчинников, В. Н. Садовский, Ю. В. Сачков, В. С. Тюхин, Э. Г. Юдин и др.),

- теория компетентностного подхода в педагогике (Н. В. Кузьмина, И. А. Зимняя, В. А. Сластенин, Г. И. Саранцев, А. И. Мищенко, Л. Ф. Спирин, А. В. Хуторской).

О характеристике процесса развития системно-интуитивного мышления на занятиях иностранного языка.

Если любую познавательную деятельность организовывать как процесс систематизированного исследования нового явления, то это приведет и к формированию определенного способа мышления. Для этого необходимо осуществить построение определенной системы, отражающей предмет изучения по технологии системного анализа. Тогда каждый фрагмент знаний рассматривается как элемент некоторой системы знаний, как элемент, имеющий конкретные смысловые связи с другими фрагментами знаний данной системы знаний. И тогда любая отрасль знаний представляется не в простом описательном виде, а в виде структуры некоторой системы.

Эта структура содержит следующие атрибуты:

- цель существования системы,

- описание источников происхождения системы,

- характеристика свойств системы как целого,

- описание свойств отдельных элементов системы,

- характеристика взаимосвязей между элементами системы,

- группирование отдельных элементов системы по различным признакам,

- выделение тех свойств системы как целого, которыми не обладает ни один из элементов этой системы,

- представление системы в фиксированный момент времени (отсут- 
ствие развития системы) и в процессе ее функционирования,

- выделение совокупности различных противоречий, главного противоречия, на основе которых происходит развитие системы.

При таком способе организации усвоения знаний обеспечиваются следующие важные характеристики профессиональной подготовки:

- знания могут использоваться практически в любых ситуациях и обеспечивать решение задач в данной области,

- совершенствуются методологические аспекты освоения знаний, когда осваиваемая предметная область рассматривается не сама по себе, а в совокупности существенных связей с другими предметными областями.

Игровой метод занимает важное место в развитии системно-интуитивного мышления. Среди игровых методов значительная роль отводится деловым играм, в которых осуществляется моделирование профессиональной деятельности будущих специалистов, моделирование взаимоотношений между ними в ходе осуществления профессиональной деятельности. В деловой игре участники совершенствуют свои знания, умения, навыки в ходе совместной деятельности. У каждого участника есть своя роль, и он при этом осуществляет определенные функции. Основным предназначением деловой игры является, прежде всего, обучение студентов совместной деятельности, обучение умениям и навыкам сотрудничества.

В настоящее время деловые игры находят широкое применение в подготовке специалистов в различных областях, а также для проведения исследований, прогнозирования, апробации планируемых новшеств. Деловые игры создаются также и в интересах развития навыков коммуникации между специалистами разных областей.

Согласно федеральным государственным образовательным стандартам среднего профессионального образования, при изучении иностранного языка необходимо учитывать профессиональную специфику. Освоение иностранного языка должно быть направлено на реализацию задач будущей профессиональной деятельности выпускников, поэтому курс обучения иностранному языку ориентирован на развитие профессиональных качеств и на развитие навыков коммуникации. Уровень освоения иностранного языка должен позволять общаться специалистам разных стран в различных сферах и ситуациях, поскольку общение на иностранном языке является важной составной частью профессиональной деятельности специалистов. В связи с этим происходит возрастание роли дисциплины «Иностранный язык» в средней профессиональной и высшей школе.

Учитывая вышеизложенное, можно сказать, что при обучении будущих юристов иностранному языку необходимо широко практиковать 
проведение деловых игр, направленных на формирование необходимых профессиональных компетенций на основе применения педагогических технологий развития системно-интуитивного мышления.

\section{О технологии контроля}

уровня развития системно-интуитивного мышления

На начальном этапе обучения иностранному языку следует произвести оценку уровня развития системно-интуитивного мышления будущих специалистов. С этой целью разрабатываются специальные задания, направленные на определение этого уровня. Задания представляют собой неформализованные тексты, содержащие описание некоторой ситуации, которую предстоит анализировать студентам. Сама ситуация относится к той предметной области, по которой осуществляется подготовка специалистов. При этом тексты характеризуются как избыточной информацией, не играющей существенной роли при анализе ситуации, так и частичным отсутствием информации, которая могла бы играть существенную роль для анализа описываемой ситуации. Задания выполняются в письменном виде.

Выполнение этих заданий включает в себя следующие этапы:

1. Выявление недостающей информации. Выявление недостающей информации осуществляется на основе интуитивных предположений;

2. Определение лишней информации с целью ее исключения из рассмотрения при проведении последующего анализа ситуации;

3. Построение когнитивной модели ситуации.

Успешное выполнение первого и второго этапов задания свидетельствует о высоком уровне развития интуитивной компоненты системноинтуитивного мышления.

Третий этап выполнения задания нацелен на развитие системной составляющей системно-интуитивного мышления.

Систематическая работа, связанная с выполнением специальных заданий на занятиях по иностранному языку, способствует развитию системно-интуитивного мышления будущих специалистов.

Оценку уровня сформированности системно-интуитивного мышления осуществляют эксперты. При этом эксперты располагают информацией только о содержании выполненного задания и не имеют информации об авторе выполненного задания. Такую оценку необходимо проводить 2 раза в семестр по 100-балльной шкале.

Оценке в 100 баллов соответствует выполнение следующих условий:

- полное выявление недостающей информации,

- полное выявление избыточной информации,

- отсутствие не выявленных существенных характеристик, описывающих ситуацию,

- отсутствие невыявленных непосредственных связей между харак- 
теристиками ситуации.

Оценке в 90 баллов соответствует выполнение следующих условий:

- выявление недостающей информации не менее чем на 90\% от общего объема недостающей информации,

- выявление избыточной информации не менее чем на 90\% от общего объема избыточной информации,

- невыявленные существенные характеристики, описывающие ситуацию, составляют не более $10 \%$ от общего числа существенных характеристик:

- невыявленные непосредственные связи между характеристиками ситуации составляют не более $10 \%$ от общего числа непосредственных связей.

Оценке в 50 баллов соответствует выполнение следующих условий:

- выявление недостающей информации не менее чем на 50\% от общего объема недостающей информации,

- выявление избыточной информации не менее чем на 50\% от общего объема избыточной информации,

- невыявленные существенные характеристики, описывающие ситуацию, составляют не более 50\% от общего числа существенных характеристик,

- невыявленные непосредственные связи между характеристиками ситуации составляют не более $50 \%$ от общего числа непосредственных связей.

Оценке в 10 баллов соответствует выполнение следующих условий:

- выявление недостающей информации не менее чем на $10 \%$ от общего объема недостающей информации,

- выявление избыточной информации не менее чем на 10\% от общего объема избыточной информации,

- невыявленные существенные характеристики, описывающие ситуацию, составляют не более $90 \%$ от общего числа существенных характеристик,

- невыявленные непосредственные связи между характеристиками ситуации составляют не более $90 \%$ от общего числа непосредственных связей.

Оценке от 0 до 9 баллов соответствует выполнение следующих условий:

- выявление недостающей информации в объеме от 0\% до 9\% от общего объема недостающей информации,

- выявление избыточной информации в объеме от 0\% до 9\% от общего объема избыточной информации,

- невыявленные существенные характеристики, описывающие ситуацию, составляют от 91\% до 100\% от общего числа существенных характе- 
ристик,

- невыявленные непосредственные связи между характеристиками ситуации составляют от 91\% до 100\% от общего числа непосредственных связей.

Оценка за все выполненное задание может быть представлена в виде кортежа <a, b, c, d>, где:

a - процент успешного выполнения первой части специального задания (от 0 до 100),

b - процент успешного выполнения второй части специального задания (от 0 до 100),

с - процент успешного выполнения третьей части специального задания (от 0 до 100),

$\mathrm{d}$ - процент успешного выполнения четвертой части специального задания (от 0 до 100).

Значения показателей a, b, c, d получают с помощью метода экспертных оценок. Затем берется среднее арифметическое оценок a, b и среднее арифметическое оценок c, d. B результате в наличии имеются две интегрированные оценки:

A - среднее арифметическое оценок a, b,

$\mathrm{C}$ - среднее арифметическое оценок c, d.

Величины оценок А, С могут изменяться в интервале от 0 до 100.

Превалирование оценки А свидетельствует о более высоком уровне развития интуитивной компоненты в системно-интуитивном мышлении, что характеризует более высокое развитие правого полушария коры головного мозга (развитое наглядно-образное мышление).

Превалирование оценки С свидетельствует о более высоком уровне развития системной компоненты в системно-интуитивном мышлении, что характеризует более высокое развитие левого полушария коры головного мозга (развитое системно-логическое мышление).

Равенство этих двух оценок подчеркивает полную гармонию в развитии системно интуитивного мышления. Чем выше значение этих оценок, тем выше уровень системно-интуитивного мышления.

\section{О порядке построения когнитивной модели деловой игры}

Существует много различных определений понятия модели. В рамках рассматриваемого вопроса наибольший интерес представляет определение, данное видным советским и российским ученым в области прикладной математики Н. Н. Моисеевым, который предложил под моделью понимать упрощенное знание, несущее определенную, ограниченную информацию о предмете или явлении, которое отражает отдельные его свойства: «Модель можно рассматривать как специальную форму коди- 
рования информации. В отличие от обычного кодирования, когда известна вся исходная информации, и мы лишь переводим ее на другой язык, модель, какой бы язык она не использовала, кодирует и ту информацию, которую люди раньше не знали. Можно сказать, что модель содержит в себе потенциальное знание, которое человек, исследуя ее, может приобрести, сделать наглядным и использовать в своих практических жизненных нуждах. Для этих целей в рамках самих наук развиты специальные методы анализа. Именно этим и обусловлена предсказательная способность модельного описания» (Малютин, Склярова, 2004: 9).

Построению когнитивной модели, которая является структурнофункциональным отражением анализируемой ситуации, предшествует работа эксперта или группы экспертов по выявлению и структуризации знаний. В ходе этой работы из первичных представлений об исследуемом процессе в ходе концептуального исследования возникает структурное знание о проблемной ситуации. Цель такой структуризации - выявление наиболее существенных факторов, характеризующих «пограничный» слой взаимодействия системы процесса и внешней среды, и установление качественных, причинно-следственных связей между ними, выявление того, какие взаимовлияния оказывают факторы друг на друга в ходе их изменения.

Моделирование на основе проведенного ситуационного анализа ложится в основу подготовки альтернативных вариантов решений по снижению степени риска в выделенных проблемных зонах, прогнозирования возможных событий, которые могут тяжелее всего отразиться на развитии процесса.

Особенность применения средств когнитивного моделирования заключается в том, что они ориентированы на конкретную ситуацию. Анализ зарубежных средств когнитивного моделирования показывает, что они не всегда успешно могут применяться в наших условиях.

Ситуации могут характеризоваться несколькими десятками различных факторов. Причем все эти факторы образуют сеть меняющихся во времени причин и следствий. Как показывают многочисленные исследования, физические, психологические данные человека ограничены возможностью одновременного просмотра не более 6-8 факторов с учетом их всех возможных взаимосвязей и взаимовлияний. Поэтому осознать логику развития ситуации на нескольких десятках факторов очень сложно, в связи с ограниченными психофизиологическими возможностями человека.

В этой связи, когнитивные модели играют очень важную роль в интересах подготовки и принятия решений в различных ситуациях. В частности, такие модели позволяют разрабатывать нормативно-правовые акты, которые достаточно хорошо соответствуют духу времени. 
Когнитивное моделирование сложных ситуаций опирается на понятие когнитивной карты ситуации. Когнитивная карта ситуации представляет собой ориентированный граф, в котором вершины взаимно однозначно соответствуют базисным факторам ситуации. Связи между вершинами (базисными факторами ситуации) определяются путем рассмотрения причинно-следственных связей, описывающих распространение влияний от каждого фактора на другие факторы. Это влияние может быть либо усиливающим (положительным), либо тормозящим (отрицательным).

Когнитивное моделирование включает в себя следующие этапы:

1. Определение начальных условий, тенденций, характеризующих развитие ситуации на данном этапе. Это необходимо для придания адекватности модельного сценария реальной ситуации, что усиливает доверие к результатам моделирования.

2. Задание целевых, желаемых направлений (увеличение, уменьшение) и силы (слабо, сильно) изменения тенденций процессов в ситуации.

3. Выбор комплекса мероприятий (совокупности управляющих факторов), определение их возможной и желаемой силы и направленности воздействия на ситуацию.

4. Выбор наблюдаемых факторов (индикаторов), характеризующих развитие ситуации. Этот выбор производится в зависимости от целей анализа ситуации.

\section{Bblводы}

Анализ особенностей юридического мышления свидетельствует о том, что профессиональная деятельность юристов, ее успех в значительной степени зависят от того, насколько у них развито системно-интуитивное мышление. Сегодня, когда на первое место выходит не просто умение читать, переводить, общаться на иностранном языке, а овладение иностранным языком как средством выражения своих мыслей способами иностранного языка и интеграция в мировой культурный процесс, современные реалии настоятельно требуют системного подхода к процессу освоения иностранного языка, в частности, через развитие системно-интуитивного мышления.

Одним из наиболее эффективных методов, способствующих развитию системно-интуитивного мышления, является игровой метод в силу хорошего сочетания его высокой эмоциональности и наглядности, способствующих повышению творческой активности студентов.

При осуществлении обучения иностранному языку будущих юристов необходимо широко практиковать на занятиях иностранного языка проведение деловых игр, направленных на становление и развитие необходимых профессиональных компетенций на основе применения педаго- 
гических технологий развития системно-интуитивного мышления.

Проведение деловых игр с применением метода когнитивного моделирования в сочетании со специальными упражнениями, развивающими интуицию и предшествующими деловой игре, способствует положительной динамике развития системно-интуитивного мышления студентов специальности 40.02.01 - Право и организация социального обслуживания среднего профессионального образования на занятиях по иностранному языку.

Дальнейшие исследования в данном направлении должны быть ориентированы на создание методологических основ системы развивающего обучения иностранным языкам для различных специальностей СПО.

\section{СПИСОК ЛИТЕРАТУРЫ}

Ильинский, И. М. (2012) Высшее образование для XXI века // Знание. Понимание. Умение. № 4. С. 3-7.

Малютин В. М., Склярова Е. А. (2004) Компьютерное моделирование физических явлений : учебное пособие. Томск: Изд-во ТПУ. 156.

Дата поступления: 30.11.2017 2.

Картакаева Эльмира Анварбековна - заместитель директора Колледжа Московского гуманитарного университета.Адрес: 111395; г. Москва, ул. Юности, д. 5, корп. 11. Тел.: +7 (499) 374-57-41. Эл. адрес: metodcab@ mosgu.ru

Kartakayeva Elmira Anvarbekovna, Deputy Director, College, Moscow University for the Humanities. Postal address: 5, Bldg. 11, Yunosti St., Moscow, Russian Federation 111295. Tel.: +7 (499) 374-57-41. E-mail: metodcab@ mosgu.ru

\section{Для циитирования:}

Картакаева Э. А. Научно-методические подходы к формированию системно-интуитивного мышления студентов-юристов колледжа на занятиях иностранного языка [Электронный ресурс] // Научные труды Московского гуманитарного университета. 2017. № 6. URL: http://journals.mosgu.ru/trudy/article/view/618 (дата обращения: дд.мм. гг.). DOI: 10.17805/trudy.2017.6.2 